\title{
A Preliminary Survey on Diversity and Conservation Status of Medium and Large-Sized Mammals in Weyngus Forest, West Gojjam Zone, Amhara Region, Ethiopia
}

\author{
Belayneh Ayechew Gelanew ${ }^{1}$ (i), Abraham Tolcha Tolla ${ }^{2 *}$ \\ ${ }^{1}$ Department of Biology, Arba Minch University, Arba Minch, Ethiopia \\ ${ }^{2}$ Biodiversity Research and Conservation Center, Arba Minch University, Arba Minch, Ethiopia \\ Email: belaynehayechw@gmail.com, ${ }^{\star}$ tolcha.abraham@yahoo.com
}

How to cite this paper: Gelanew, B.A. and Tolla, A.T. (2022) A Preliminary Survey on Diversity and Conservation Status of Medium and Large-Sized Mammals in Weyngus Forest, West Gojjam Zone, Amhara Region, Ethiopia. Open Journal of Ecology, $12,149-161$.

https://doi.org/10.4236/oje.2022.122009

Received: January 11, 2022

Accepted: February 18, 2022

Published: February 21, 2022

Copyright $\odot 2022$ by author(s) and Scientific Research Publishing Inc. This work is licensed under the Creative Commons Attribution International License (CC BY 4.0).

http://creativecommons.org/licenses/by/4.0/

\begin{abstract}
Mammalian surveys are vital tools for effective managements and conservation strategies. A survey was conducted to investigate the species composition, relative abundance and to determine their major threats in Weyngus Forest, West Gojjam Zone, Amhara Region, Ethiopia. The data were collected from April 2020 to June 2020. Transect method and subjective interviews were used to collect data for the study. A total of 11 species of medium and large sized mammals belonging to six orders and eight families were recorded by direct and indirect evidences. Porcupine (Hystrix cristata), Vervet monkey (Chlorocebus aethiops), and Coloubus monkey (Colobus guereza) were among the medium-sized mammals while, Spotted hyena (Crocuta crocuta), Bushbuck (Tragelaphus scriptus) and Common duiker (Sylvicapra grimmia) were among the large-sized mammals recorded in the study area. Vervet monkey has been the most frequently observed species, whereas spotted hyena was observed less often. Simpson's Similarity Index (SI) showed a significant overlap of mammalian species composition between scrubland and natural forest $(S I=0.62)$. Illegal logging of trees for fuel wood, agricultural land expansion, illegal hunting and land degradation were the main threats of mammals in the study area. Community participation and awareness creation are highly recommended to limit the impact of anthropogenic activities threatening wildlife.
\end{abstract}

\section{Keywords}

Anthropogenic Activity, Mammals' Survey, Relative Abundance,

Threats of Mammals 


\section{Introduction}

Mammals are among the most widely distributed organisms in the world and occur from the Antarctic to desert ecosystems [1]. They are the most successful groups of animals next to the arthropods in the globe. This is due to their diversity in size and morphology, physiology, behavioral adaptation, and colonizes diverse habitat types [2]. Total of 5416 number of living species of mammals occurs around the globe. Of these, 2277 (42\%) rodents (Rodentia), 1116 (20.6\%) bats (Chiroptera), and 428 (7.9\%) shrews and allies (Soricomorpha) comprise the largest species [3] [4].

Ethiopia is a home to a wide diversity of flora and fauna due to its' suitable ecological, edaphic and climatic conditions [5] [6]. It has 311 species of mammal fauna, fitting to 144 genera. Of these, 55 mammalian species are endemic to Ethiopia [7]. As a result, the country ranks among the most diverse mammalian faunas in Africa. Mammals provide different purposes such as; economic, cultures and beliefs, educational and scientific values and source of food and income generation like tusks, horns, and ivory [8]. They have also a great role in ecosystem services like in seed dispersal, regulate prey populations, and in nutrient cycling [3].

Due to low reproductive rates, large body size, habitat fragmentation, overexploitation, and low rate of body growth, low generation time and requirement of large area mammals are facing greater population declines [9] [10]. Among the known species of mammals, $25 \%$ are threatened, $11 \%$ are endangered, $4 \%$ are critically endangered and approximately $2 \%$ of the known modern day mammals have gone extinct in the last 400 [11]. Hence, mammalian inventories are key implements to increase conservation policies and mammalian management [12] [13]. There are several previous studies conducted on mammal's diversity, distribution and other ecological aspects mainly targeted in National Parks and Sanctuaries of the country. But research conducted outside those areas like protected forest, agricultural land and other fragmented habitats are very small. Therefore, mammalian inventories in previously unexplored area will contribute to further research and to the amplification of strategies and new measures for the conservation of medium- and large-sized mammals in Weyngus protected forest. The purpose of this study was to articulate medium and large-sized mammals' diversity and to contribute to designing future conservation policies on conservation challenges and biodiversity in Weyngus protected forest, aiming to have knowledge of the mammalian fauna and would provide baseline information on species regarding conservation status in the study area.

\section{Materials and Methods}

\subsection{Description of the Study Area}

Weyngus forest is located in Dega Damot District which is one of the fourteen districts of west Gojjam administrative zone of the Amhara region Ethiopia. It is $271 \mathrm{~km}$ far from Bahir Dar, the capital city of Amhara Regional state, and 401 
$\mathrm{km}$ North of Addis Ababa, Ethiopia. The district has three major agro-ecological zones; Dega (75\%), Woina Dega (20\%) and Kola (5\%). The annual rainfall ranges between 900 and $1200 \mathrm{ml}$ [14]. Tigrie Engada is one of the 33 Peasant Association found in the district. All the peoples are followers of the Ethiopian Orthodox Tewahedo Church. Weyngus forest is one of protected forest in Tigrie Engada Peasant Association. It is surrounded by four rural peasant associations namely; Taime abekidan, Gelila, Amija wefchaina and Dingayber Hagere mariyam and is found in the north, south, East and West of the study area respectively (Figure 1).

There are five rivers in the study area, Guacha River flows continuously throughout the year. It is known for use of different wild animals in the forest and livestock's of the surrounding community. The area has more than five large and small caves, especially two of them are well known by the surrounding people. These caves are locally named as a Serval cat cave (in Amharic language named

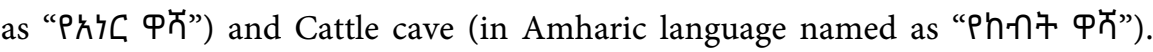
Peoples use "Cattle cave" as shelter to their livestock from rain during the wet season. This cave has a competency of holding more than 50 cattle at the same time (Figure 2).

Ekebergia capensis, Ficus sur, Schefflera abyssinica, Rosa abyssinica, Dovyalis abyssinica, Maesa lanceolata, Dombeya torrida and plantations like Eucalyptus species and Bamboo species are the predominantly covering tree species of the area while, Urera hypselodendron, Vernonia amygdalina, Laggera tomentosa, are commonly found herbs species in the area. Bushbuck, Common jackal, Guereza and Vervet monkey are mammalian species commonly found in the area. Different rodent species and avian fauna are also found in this forest. The surrounding people obtain various ecosystem services from the forest, such as foods

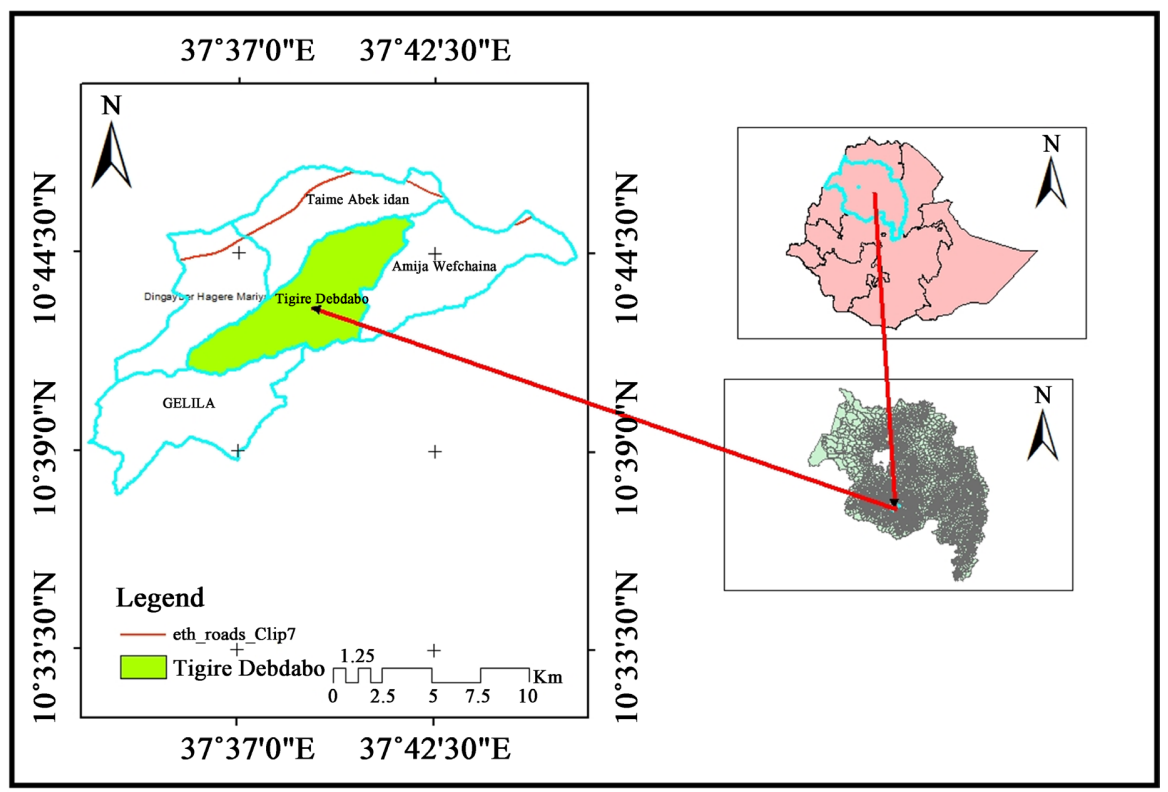

Figure 1. Map of the study area. 


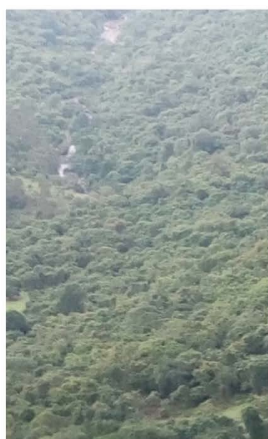

(a)

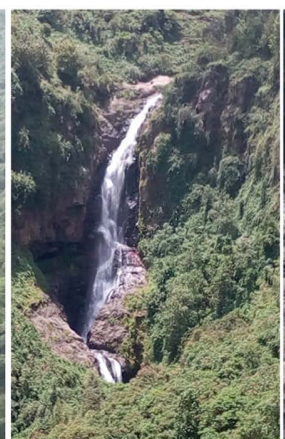

(b)

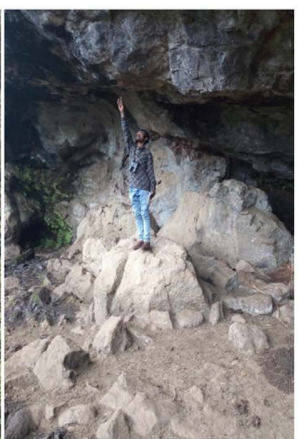

(c)

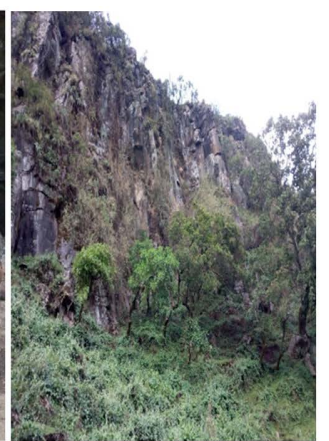

(d)

Figure 2. Weyngus natural forest (a), water falls of Guacha river found at the left tips of the forest (b), cave used as shelter to livestock from rain during the wet season (c) and rocky and mountainous view of the area (d) (April, 2020; Photo: Anesekegn A.).

(e.g. from Rosa abyssinica, African mulberry and Dovyalis abyssinica); soap (from Phytolacca dodecandra) and different home-grown materials (e.g. from Eucalyptus spp, bamboo species, Dombeya torrida).

\subsection{Preliminary Survey}

Reconnaissance was made in the first weeks of April 2020 to get basic information on accessibility, vegetation type, and topography of the area. The dominant habitat types were transverse on foot and visual estimation of the area of each habitat type was made.

\subsection{Sampling Design}

Based on direct observation made during the reconnaissance survey the study area was stratified into four dominant habitat types, these are; natural forest (the forest that grow naturally), human plantations (which are intensively managed stands of trees that have been artificially planted tree species), bar land (the land grasses growing on it but not tree species) and scattered tree (trees distributed or occurring at widely spaced intervals). Different plant species are dominated in each habitat type. The most abundant plant species were identified in the field based on the recorded direct book [15]. This is also supported by familiar peoples living adjusts to the area. Natural forest habitat principally consists of long and large tree species such as Maytenus senegalensis, Geteme Schefflera abyssinica, Ekebergia capensis and Maesa lanceolata. Plantation commonly consists of Eucalyptus spp and Bamboo species. On the other hand, bare land habitat mainly dominated by different grass species, while the scattered tree habitat largely consist of dispersed plant species of Dombeya torrida, Buddleja polystachya and Rosa abyssinica. A total of eight transect lines (which are fragmented due to the topographic nature of the area) were established to cover the major habitat types. Of these, three in natural forest, two in bar land, two in scattered tree habitat and one in human plantations were laid. These transect lines were placed on the stratified habitat types in a randomly fashion and proportional to the area 
of every habitat type as discussed by Varman and Sukumar [16].

\subsection{Methods of Data Collection}

An investigation on medium and large mammals were conducted from April 2020 to June 2020 using line transect method. Both direct and indirect survey techniques were employed [13] [17]. A survey was conducted in the early morning from 6:00 to 10:00 and late afternoon from 16:00 to 19:00 when the animals are more active [13] [18]. When counting the mammals, one researcher and two filed assistance were walking on foot along the pre-established line transect in order to count all the individuals sighted and record indirect evidence of the animal presence in the area. Observation of individual and categories with their respective species was done using unaided eyes and/or binocular $(9 \times 35$ COMPACT WIDE $131 \mathrm{M}$ AT $1000 \mathrm{M})$. To minimize disturbance during counting, silent movement followed by 3 to 5 minutes waiting period was allowed. Each encountered species of large and medium sized mammals was identified in the field using Kingdon Field Guide to African Mammals [19]. Mammals weighting between 2 and $7 \mathrm{~kg}$ were considered as a medium sized while, weighing above $7 \mathrm{~kg}$ were considered as large mammals as applied by Sutherland [20]. The conservation status of medium and large-sized mammals in the study area was addressed through key informant interview and field observation. A total of 18 people (six from each village) were selected for interview based on their long years lived adjacent to the area and their extensive knowledge of the local fauna. Interviews were mainly focused on mammal species existing in the forest and their major threats.

\subsection{Data Analysis}

Shannon-Wiener diversity index and Shannon-Wiener evenness index [21] was used to analyses species diversity of medium and large-sized mammals and species evenness respectively. Simpson similarity index (SI) was also computed to assess the similarity of mammalian species composition among habitats. The relative abundance of each species was calculated by dividing the number of records of each species by the total number of records of all species in the study area. The abundance of observed mammals were categorized as "common" if they were seen during all of the surveys "uncommon" if they were seen in more than half of the surveys, and "rare" if seen less than half of the surveys period following Legese et al. [13]. Interview surveys on the threats of mammals were analysed using SPSS version 20 software, while direct filed observations on the threats of mammals were presented descriptively.

\section{Results}

\subsection{Species Composition}

Within a total of 126 observations, 11 species of medium and large sized mammals were recorded. Those mammals are belonging to six orders and eight fami- 
lies. Seven (63.6\%) species were identified by direct sightings; two (18.2\%) species were recorded through indications of body parts and vocalization whereas, two (18.2\%) species were recorded by evidences obtained from interviewing of local peoples. Order Carnivora had the highest number of species with four species followed by Primates and Artiodactyla with two species each. All the remaining orders were represented by a single species each. At family level, Bovidae, Cercopithecidae, and Canidae had contained two species each; while all the remaining families were represented by a single species each in the study area (Table 1). Spotted hyena and Porcupine were exclusively identified from indirect evidences (scat, spines, footprint and vocalization) but the presence of Serval cat and Bat-eared fox $(\hbar \$ 3)$ were guaranteed by villagers. Most $(n=14$, $77.8 \%$ ) of the interviewed peoples claimed that leopard has been an inhabitant of the area before a three years ago, which were illegally hunted. On the other hand, a small number $(\mathrm{n}=4,22.2 \%$ ) of respondents suggested as they have observed this animals in the area very rarely. But, during our filed survey neither direct nor indirect evidences were observed at all.

\subsection{Distributional Patterns and Abundance}

The distributional patterns of medium and large sized mammals were varied across the study habitats. High number of species was observed in the natural forest (8 species) whereas; a single species was recorded in bar land habitat. Of the total observed species two (22.2\%) species were observed in three of the four habitats, while four $(44.5 \%)$ species were recorded from two habitat types. On the other hand three (33.3\%) species were limited to a single habitat type (Table 2).

Among the 11 species of mammals, Vervet monkey was the dominant mammalian species followed by Guereza, Ethiopian rock hyrax, and Porcupine while,

Table 1. Medium and large sized mammal species composition and their mood of recording in Weyngus forest $\left(\right.$ key: ${ }^{*}=$ visual, $¥=$ vocalization, $€=$ personal communication, $\mathfrak{E}=$ scat $/$ spines $)$.

\begin{tabular}{|c|c|c|c|c|c|}
\hline Order & Family & Scientific name & Common name & Local name & Mood of recording \\
\hline \multirow{2}{*}{ Artiodactyla } & \multirow{2}{*}{ Bovidae } & Sylvicapra grimmia & Bush duiker & Midako & * \\
\hline & & Tragelaphus scriptus & Bushbuck & Dekula & * \\
\hline Hyracoidea & Procaviidae & Procavia capensis & Ethiopian Rock Hyrax & Eshekoko & * \\
\hline Lagomorpha & Leporidae & Lopus starkii & Rabbit & Tenchel & * \\
\hline \multirow{2}{*}{ Primates } & \multirow{2}{*}{ Cercopithecidae } & Colobus guereza & Guereza & Gureza & * \\
\hline & & Chlorocebus aethiops & Vervet monkey & Tota & * \\
\hline \multirow{4}{*}{ Carnivora } & Hyeaniadea & Crocuta crocuta & Spotted hyena & Jib & $¥, €$ \\
\hline & Felidae & Felis Serval & Serval cat & Aner & $€$ \\
\hline & \multirow{2}{*}{ Canidae } & Otocyon megalotis & Bat-eared fox & Afine & $€$ \\
\hline & & Canis aureus & Common jackal & Kebero & * \\
\hline Rodentia & Hystricidae & Hystrix cristata & Porcupine & Jart & $\mathfrak{E}$ \\
\hline
\end{tabular}


Table 2. Medium and large sized mammal species distribution, occurrence and relative frequency observations during the survey period (Key: ${ }^{\star}$ their presence is assured by the villagers', - no direct observed).

\begin{tabular}{|c|c|c|c|c|c|c|c|}
\hline \multirow[b]{2}{*}{ Scientific name } & \multirow[b]{2}{*}{ Occurrence } & \multicolumn{4}{|c|}{ Habitat types } & \multirow{2}{*}{$\begin{array}{c}\text { Total } \\
\text { observation }\end{array}$} & \multirow{2}{*}{$\begin{array}{c}\text { Relative } \\
\text { frequency } \\
\text { observation }\end{array}$} \\
\hline & & $\begin{array}{c}\text { Natural } \\
\text { forest }\end{array}$ & $\begin{array}{c}\text { Human } \\
\text { Plantation } \mathrm{n}\end{array}$ & $\begin{array}{l}\text { Scattered } \\
\text { tree }\end{array}$ & Bar land & & \\
\hline Sylvicapra grimmia & Rare & 6 & 2 & - & - & 8 & 6.3 \\
\hline Tragelaphus scriptus & Rare & 3 & 1 & - & - & 4 & 3.1 \\
\hline Procavia capensis & Rare & - & - & 12 & - & 12 & 9.4 \\
\hline Lopus starkii & Rare & 2 & 1 & - & - & 3 & 2.4 \\
\hline Colobus guereza & Common & 37 & - & - & - & 37 & 29.1 \\
\hline Chlorocebus aethiops & Common & 23 & 16 & 13 & - & 52 & 41 \\
\hline Crocuta crocuta & Rare & 2 & - & - & - & 2 & 1.6 \\
\hline Felis Serval & * & - & - & - & - & & \\
\hline Otocyon megalotis & * & - & - & - & - & & \\
\hline Canis aureus & Rare & 2 & 1 & - & - & 3 & 2.4 \\
\hline Hystrix cristata & Rare & 3 & 1 & - & 2 & 6 & 4.7 \\
\hline
\end{tabular}

Bushbuck, Spotted hyena, and Common jackal were the least common species in the study area. Regarding to the occurrence of mammals based on their frequency of observation through the study interval, Vervet monkey and Guereza were common, while all the remaining observed mammals were rare.

\subsection{Species Diversity and Evenness}

The highest diversity of mammals was recorded from natural forest habitat $(\mathrm{n}=$ 8) followed by human plantation $(n=6)$ and scattered tree $(n=2)$ in the area. Nevertheless, only a single species was seen in the bar land habitat, as a result no species diversity here. The Sorensen species similarity index of medium and large sized mammal species was varied between and among habitat.

Medium and large sized mammalian similarity was high between natural forest and human plantation ( $\mathrm{SI}=0.857$ ) followed by bar land and human plantation $(S I=0.285)$, and human plantation and scattered tree $(S I=0.25)$. But, there was no observed mammalian species evenness between scattered tree and bar land $(\mathrm{SI}=0.000)$. The species similarity among natural forest, bar land and human plantation $(S I=0.133)$ was slightly smaller than among natural forest, human plantation and scattered tree ( $\mathrm{SI}=0.125)$.

On the other hand, the highest evenness of the mammalian species was recorded in scattered tree $(E=0.995)$ followed by natural forest $(E=0.689)$ and human plantation $(E=0.560)$. Similarly, the highest Simpson's index $(1-D)$ of mammalian species was recorded from the natural forest habitat $(0.682)$ whereas; no species diversity was recorded in bar land habitat (0.000), where only a single species was observed there. The overall species richness of Weyngus forest 
was 11 , and Shannon-Wiener Index values were low $\left(H^{\prime}=1.603\right)$ whereas the Simpson's index of diversity showed the highest species diversity (0.736) in the current study area (Table 3 ).

\subsection{Major Threats to Mammals of Weyngus Forest}

All of the respondents $(n=18 ; 100 \%)$ mentioned that illegal hunting was the major threats of medium and large-sized mammals followed by fuel wood $(\mathrm{n}=$ $14,77.76 \%)$, land degradation ( $9 ; 50 \%)$, agricultural land expansion ( $\mathrm{n}=5 ; 27.78 \%$ ) and grazing $(\mathrm{n}=3 ; 16.66 \%)$. Stastically significant variation was observed among threats in the study area $\left(\chi^{2}=15.796, \mathrm{df}=4, \mathrm{p}=0.003\right)$. Furthermore, they stated as cutting forest for fuel wood and fencing are takes place during the night time using hand saw, which prevent peoples from hearing the sound while cutting and they can easily take away. During our field observations, land degradation and different anthropogenic activities such as agricultural land expansion, illegal logging and wood collection for fuel and for construction were reputedly observed (Figure 3).

Table 3. Medium and large mammal richness and diversity indices during the survey period.

\begin{tabular}{|c|c|c|c|c|c|}
\hline \multirow[b]{2}{*}{ Variables } & \multicolumn{4}{|c|}{ Habitats } & \multirow{2}{*}{$\begin{array}{l}\text { Overall } \\
\text { diversity } \\
\text { indices }\end{array}$} \\
\hline & $\begin{array}{c}\text { Natural } \\
\text { forest }\end{array}$ & $\begin{array}{c}\text { Human } \\
\text { plantation }\end{array}$ & $\begin{array}{l}\text { Scattered } \\
\text { tree }\end{array}$ & Bar lands & \\
\hline No. of species & 8 & 6 & 2 & 1 & 11 \\
\hline No. individuals & 78 & 22 & 25 & 2 & 127 \\
\hline SWI (H’) & 1.433 & 1.003 & 0.690 & 0.000 & 1.603 \\
\hline $\mathrm{H}_{\max }$ & 2.079 & 1.791 & 0.693 & 0.000 & 2.397 \\
\hline $\begin{array}{l}\text { Simpson's index of } \\
\text { diversity (1-D) }\end{array}$ & 0.682 & 0.477 & 0.479 & 0.000 & 0.736 \\
\hline Evenness & 0.689 & 0.560 & 0.995 & 0.000 & 0.668 \\
\hline
\end{tabular}

Figure 3. Major threats to mammals of Weyngus forest (land degradation (a), logging for fuel wood (b) and for other infrastructures like, timber (c) (May, 2020; Photo: Belayneh Ayechew)). 


\section{Discussion}

Using direct and indirect evidence, a total of 11 species of medium and largesized mammals were identified in the current study area. Within a comparable survey period, Legese et al. [13] found 12 mammal species in Wabe forest remnants, Gurage zone, Ethiopia. On the other hand, at the Baroye Controlled Hunting Area in Southwestern Ethiopia a large number of animal species (23 species) were discovered [22]. This difference could be owing to the study area's modest size and the survey period's short duration in Weyngus forest. Furthermore, during the study period, agricultural land expansion, illegal logging for fuel wood, overgrazing, and illegal hunting were all regular occurrences. Typically, these have significant negative effects on the fauna of animals. Limited survey length, research area size, and habitat changes caused by diverse anthropogenic pressures all have a major impact on species' existence, abundance and distribution [13] [23] [24].

Similar to other mammalian studies, [3] [23] [25] [26] [27] [28], the current study found that mammals choose one habitat over another based on resource availability and quality. In the current investigation, a great number of species of medium and big mammals were discovered in the natural forest. This is due to the natural forest's lower disturbance rate and greater availability of high-quality food compared to other habitat types. Moreover, Tilahun and Merewa [18], Qufa and Bekele [23], Belete and Melese [27] and Bobo et al. [29] reported that high species diversity of mammals was recorded either in woodlands and/or forest habitats.

The most common species seen were vervet monkeys, followed by Colobus gureza. The topographic features of the current research area are ideal for primate populations. Primate is the most abundant order in various study areas, according to several studies [3] [13] [28]. Beyond their abundance in varied places, Bobo et al. [29] argued those primates' high reproductive success, diversified feeding habits, and more adaptable nature is a factor.

The order Artiodactyla was placed second in terms of distribution and abundance after the order primate. Legese et al. [13] reported a similar finding. Nonetheless, this discovery contradicts Geleta and Bekele's [3] and Qufa and Bekele's [23] findings. This difference could be a result of the change in the availability of resource in each study area. Procavia capensis thrives in the presence of rocks and caves in the hilly areas of the current study area. Carnivores were few in the research area, both in terms of distribution and number. The existence of unlawful hunting due to large depredations of livestock by carnivores (particularly, Spotted hyena and Bat eared-fox) in and around the research region greatly reduces their number, according to respondents. Their presence could not be easily documented due to human intervention in their nocturnal and cryptic activities, according to Gonfa et al. [26].

The order Lagomorpha had the smallest distribution and abundance in the Weyngus forest. In this order, only one species, Lopus starkii, was represented. Because Lopus starkii is a common crop raider, the respondents decided that it 
was hunted. As a result of the struggle, their numbers began to dwindle over time. In and around the Weyngus forest, human-wildlife conflicts are a typical occurrence [29]. Similarly, the order Rodentia has only one species, Hystrix cristata. In Wacha protected woodland, Western Ethiopia, Geleta and Bekele [3] stated as order Lagomorpha, Hyracoidea, and Rodentia were each represented by a single species. The natural forest and the human plantation shared the most species similarities. This is most likely owing to the fact that these habitats are located near rivers and mountain ranges, which allows them to hide from potential enemies. The species evenness among the habitats is mostly determined by the proximity of different habitats to one another, differences in sampling attempts, and animal utilization of habitats [13] [29].

Of all, $9(81.82 \%)$ of the species were rare while, $2(18.18 \%)$ were common in the study area. Most mammals are under local threat; especially Tragelaphus scriptus. During a field survey, we discovered that this Bovidae was being illegally hunted for meat. The common mammalian risks in the research area included land degradation, agricultural land expansion, illegal logging for fuel wood and illegal hunting. In and around the research area, human-wildlife conflict is claimed to be a common concern [30]. Similar reported as discussed by Tilahun and Merewa [18]. Agreeing to Legese et al. [13], the main stresses in Wabe forest fragments are substantial habitat fragmentation, deforestation, expansion of roads and human settlements, and infrastructure expansions such as highways. Other studies, such as Qufa and Bekele [23], Espinosa et al. [31], Worku and Girma [32] and Wale et al. [33] have documented comparable trends in other study areas in Ethiopia and internationally.

In conclusion, Tragelaphus scriptus is the most vulnerable and highly threatened species in the Weyngus protected forest, out of a total of 11 species of medium and large mammals recorded. As a result, additional considerations should be made before it becomes extinct locally. In addition, the research area's shared hazards included land degradation, agricultural land expansion and illegal logging for fuel wood. It is significantly more beneficial to use religion to create community awareness and manage the forest than to rely on the law. Furthermore, the head of the Dega Damot district and the Tigrie Engada Peasant Association should collaborate with the local population to establish a restoration program to secure the survival of mammals in the Weyngus protected forest. We further recommend that more extensive research on mammalian ecology and other related areas be conducted in both wet and dry seasons, since the current study did not.

\section{Acknowledgements}

We appreciate everyone who took the time to provide us with accurate information and their time. We also like to thank Bethlehem Zeleke, the leader of the Tigrie Engada Peasant Association, for providing the necessary data and allowing us to conduct our research in the Weyngus protected forest. Last but not 
least, we would like to express our gratitude to Enyew A and Senamaw T for their support with data gathering.

\section{Conflicts of Interest}

The authors declare no conflicts of interest regarding the publication of this paper.

\section{References}

[1] Jenkinsa, C.N., Pimmb, S.L. and Joppac, L.N. (2013) Global Patterns of Terrestrial Vertebrate Diversity and Conservation. Proceedings of the National Academy of Sciences of the United States of America, 110, E2602-E2610. https://doi.org/10.1073/pnas.1302251110

[2] Ceballos, G. and Ehrlich, P.R. (2006) Global Mammal Distributions, Biodiversity Hotspots, and Conservation. Proceeding of the National Academy of Science, USA, 103, 19374-19379. https://doi.org/10.1073/pnas.0609334103

[3] Geleta, M. and Bekele, A. (2016) Survey of Medium and Large-Sized Mammals in Wacha Protected Forest, Western Ethiopia. Scholarly Journal of Agricultural Science, 6, 71-79.

[4] Wilson, D.E. and Reeder, D.M. (2005) Mammal Species of the World: A Taxonomic and Geographic Reference. 3rd Edition, Johns Hopkins University Press, Baltimore, 2142.

[5] Tefera, M. (2011) Wildlife in Ethiopia: Endemic Large Mammals. World Journal of Zoology, 6, 108-116.

[6] Smith, M.L., Noonan, B.P. and Colston, T.J. (2017) The Role of Climatic and Geological Events in Generating Diversity in Ethiopian Grass Frogs (Genus Ptychadena). Royal Society Open Science, 4, 8. https://doi.org/10.1098/rsos.170021

[7] Lavrenchenko, A.L. and Bekele, A. (2017) Diversity and Conservation of Ethiopian Mammals: What Have We Learned in 30 Years? Ethiopian Journal of Biological Science, 16, 1-20.

[8] Boesch, L., Mundry, R., Kühl, S.H. and Berger, R. (2017) Wild Mammals as Economic Goods and Implications for Their Conservation. Ecology and Society, 22, 36. https://doi.org/10.5751/ES-09516-220436

[9] Vaughan, A.T., Ryan, M.J. and Czaplewaki, N. (2000) Mammalogy. 4th Edition, Saunders College Publishing, New York.

[10] Cardillo, M., Mace, G.M., Jones, K.E., Bielby, J., Bininda-Emonds, O.R.P., Sechrest, W., Orme, C.D.L. and Purvis, A. (2005) Multiple Causes of High Extinction Risk in Large Mammal Species. Science, 309, 1239-1241. https://doi.org/10.1126/science. 1116030

[11] IUCN (1996) 1996 IUCN Red List of Threatened Animals. IUCN, Gland.

[12] Keeping, D. and Pelletier, R. (2014) Animal Density and Track Counts: Understanding the Nature of Observations Based on Animal Movements, PLOS ONE, 9, e96598. https://doi.org/10.1371/journal.pone.0096598

[13] Legese, K., Bekele, A. and Kiros, S. (2019) A Survey of Large and Medium-Sized Mammals in Wabe Forest Fragments, Gurage Zone, Ethiopia. International Journal of Avian and Wildlife Biology, 4, 32-38. https://doi.org/10.15406/ijawb.2019.04.00149

[14] Liyew, B., Tamrat, B. and Sebsebe, D. (2017) Woody Species Composition and Struc- 
ture of Amoro Forest in West Gojjam Zone, North Western Ethiopia. Journal of Ecology and the Natural Environment, 10, 53-64. https://doi.org/10.5897/JENE2018.0688

[15] Bekele, T., Birnie, A. and Tenqnas, B. (1993) Useful Trees and Shrubs for Ethiopia: Identification, Propagation and Management for Agricultural and Pastoral Communities, Regional Soil Conservation Unit/SIDA. Swedish International Development Authority (SIDA).

[16] Varman, K.S. and Sukumar, R. (1995) The Line Transect Method for Estimating Densities of Large Mammals in a Tropical Deciduous Forest: An Evaluation of Models and Field Experiments. Journal of Bioscience, 20, 273-287. https://doi.org/10.1007/BF02703274

[17] Larsen, T.H. (2016) Core Standardized Methods for Rapid Biological Field Assessment. Conservation International, Arlington.

[18] Tilahun, Z. and Merewa, Z. (2020) Large Mammal Diversity and Endemism at Geremba Mountain Fragment, Southern Ethiopia. International Journal of Ecology, 2020, Article ID: 3840594. https://doi.org/10.1155/2020/3840594

[19] Kingdon, J. (1997) The Kingdon Field Guide to African Mammals. Academic Press, London.

[20] Sutherland, J.W. (2006) Ecological Census Techniques. 2nd Edition, University of East Anglia, Norwich. https://doi.org/10.1017/CBO9780511790508

[21] Shannon, G.E. and Weaver, W. (1949) The Mathematical Theory of Communication. University of Illinois Press, Chicago.

[22] Dereje, N., Tsegaye, G. and Tadese, H. (2015) The Diversity, Distribution and Relative Abundance of Medium and Large-Sized Mammals in Baroye Controlled Hunting Area, Illubabor Zone, Southwest Ethiopia. International Journal of Molecular Evolution and Biodiversity, 5, 1-9.

[23] Qufa, C.A. and Bekele, A. (2019) A Preliminary Survey of Medium and Large-Sized Mammals from Lebu Natural Protected Forest, Southwest Showa, Ethiopia. Ecology and Evolution, 9, 12322-12331. https://doi.org/10.1002/ece3.5733

[24] Link, A., Luna, A. and Alfonso, F. (2010) Initial Effects of Fragmentation on the Density of Three Neotropical Primate Species in Two Lowland Forests of Colombia. Endangered Species Research, 13, 41-50. https://doi.org/10.3354/esr00312

[25] Alves, B.G., Junior, M.O. and Brites, V.C. (2014) Medium and Large-Sized Mammals of a Fragment of Cerrado in the Triângulo Mineiro Region, Southeastern Brazil. Bioscience Journal of Uberlandia, 30, 863-873.

[26] Gonfa, R., Gadisa, T. and Habtamu, T. (2015) The Diversity, Abundance and Habitat Associations of Medium and Large-Sized Mammals in Dati Wolel National Park, Western Ethiopia. International Journal Biodiversity Conservation, 7, 112-118. https://doi.org/10.5897/IJBC2014.0808

[27] Belete, T. and Melese, M. (2016). Assessment of Large Mammal's Potential in Tululujia Wildlife Reserve, Southwestern Ethiopia. International Journal of Agricultural and Life Sciences, 2, 80-86.

[28] Atnafu, G. and Yihune, M. (2018) Species Composition and Relative Abundance of Medium and Large Mammals in Mengaza Communal Forest, East Gojjam, Ethiopia. Journal of Ecology and the Natural Environment, 10, 34-40. https://doi.org/10.5897/JENE2017.0667

[29] Bobo, S., Kamgaing, L. and Ntumwel, C. (2014) Species Richness, Spatial Distributions, and Densities of Large- and Medium-Sized Mammals in the Northern Peri- 
phery of Boumba bek National Park, Southeastern Cameroon. African Study Monographs, 49, 91-114.

[30] Ayechew, B. and Tolcha, A. (2020) Assessment of Human-Wildlife Conflict in and around Weyngus Forest, Dega Damot Woreda, West Gojjam Zone, Amhara Region, Ethiopia. International Journal of Scientific Engineering and Science, 4, 1-10.

[31] Espinosa, C.C., Galiano, D., Kubiak, B.B. and Marinho, J.R. (2016) Medium- and Large-Sized Mammals in a Steppic Savanna Area of the Brazilian Pampa: Survey and Conservation Issues of a Poorly Known Fauna. Brazilian Journal of Biology, 76, 73-79. https://doi.org/10.1590/1519-6984.12714

[32] Worku, Z. and Girma, Z. (2020) Large Mammal Diversity and Endemism at Geremba Mountain Fragment, Southern Ethiopia.

https://doi.org/10.1155/2020/3840594

[33] Wale, M., Kassie, A., Mulualem, G., Tesfahunegny, W. and Assefa, A. (2017) Wildlife Threats and Their Relative Severity of Eastern Ethiopia Protected Areas. Ecology and Evolutionary Biology, 2, 59-67. https://doi.org/10.11648/j.eeb.20170204.12 